\title{
Spatio-temporal Differences in the Filipinos' Search Trends for Toothache and Milk Tea
}

\author{
Junhel Dalanon, DMD, MAT, EdD, PhD (cand),1,2 Liz Muriel Diano, DMD¹ and Yoshizo Matsuka, DDS, PhD² \\ ${ }^{1}$ School of Dentistry, Southwestern University PHINMA \\ ${ }^{2}$ Department of Stomatognatbic Function and Occlusal Reconstruction, Tokushima University Graduate School, Japan
}

\begin{abstract}
Background. Since 1987, data regarding dental caries prevalence in the Philippines has been shown to be over $90 \%$.

Objective. This study compared the trends of Filipino web searches regarding toothache and milk tea from 2017 to 2019 through spatio-temporal analyses.

Methods. Google Trends searches for the years 2017, 2018, and 2019 were done using three separate search queries using the parameters "toothache" (TA) and "milk tea" (MT) as search terms, Philippines as location, Health as category, and Web Search as database.

Results. The outcome showed a decreasing trend in searches for toothache and an increasing interest for milk tea web searches from 2017 to 2019. A multiple comparison test showed that searches for MT were significantly more than TA in 2017 ( $p<0.001), 2018$ ( $p<0.001)$, and 2019 ( $p<0.001)$. Searches for TA during the $2^{\text {nd }}$, $3^{\text {rd }}$, and $4^{\text {th }}$ quarter compared to the $1^{\text {st }}$ quarter of the year, in Caraga, Eastern Visayas, Western Visayas and Zamboanga Peninsula compared to Manila, were found to be significantly high.
\end{abstract}

Conclusion. Filipinos' health-seeking behavior show decreasing interest towards TA and increasing for MT.

Key Words: spatio-temporal analysis, data mining, health-seeking behavior, dental care, Philippines

\section{INTRODUCTION}

From 1987 to 1998, the prevalence of dental caries decreased at a rate of $1.5 \%$ only. The expression of the average number of permanent teeth (decayed, missing, and filled teeth (DMFT)) or temporary that are decayed, indicated for filling or extraction is a measure of the severity of tooth decay. A 2006 National Oral Health Survey found a high tooth decay prevalence for the six-year-old (8.4 DMFT) and a decreasing trend for the twelve-year-old (2.9 DMFT) Filipino children. An increasing trend was seen in the age group of 35-44 age group from 1982 (14.18 DMFT) to 1998 (15.04 DMFT). ${ }^{1}$

A study done in Benguet found the high prevalence of dental caries increases with added sugar consumption. They have attributed this to extensive neglect of oral health and the freely-available dietary products rich in refined sugars. Caries rates were similar to developing countries with untreated

Corresponding author:

Junhel Dalanon, DMD, MAT, EdD, PhD (cand.)

School of Dentistry

Southwestern University PHINMA

Urgello St., Cebu City, Philippines 6000

Email: jcdalanon@swu.edu.ph oral health conditions that were predominant across all ages. ${ }^{2}$ Genetic predisposition affecting salivary flow and diet preference have been found to contribute to high caries susceptibility in Filipinos. ${ }^{3}$ Dental caries was also found to be associated with demographic, socioeconomic conditions, 
and body mass index (BMI). This is substantially important in the Philippines because of its archipelagic structure, being classified as a low middle-income economy, and children being underweight as a consequence. ${ }^{4}$ The 2011 National Monitoring and Evaluation Dental Survey (NMEDS) done by the Department of Health (DOH) revealed that dental caries remains to be one of the most common oral diseases at a prevalence of $87.4 \% .^{5}$ But despite the Oral Health Care Package $(\mathrm{OHCP})^{1}$ and the Fit-for-School program ${ }^{6}$ of the $\mathrm{DOH}$, dental caries prevalence still remains high and unsolved. ${ }^{7}$

The individual and joint advantages of milk and tea have been documented. ${ }^{8-12}$ Despite the antioxidant benefits on skin and oral cancer risk, the disadvantages of vascular protective effects reduction of tea, ${ }^{13}$ increased obesity risk, and high caries tendency outweighs them. ${ }^{14}$ The beneficial effect of drinking tea also requires a person to drink it every two hours. ${ }^{11}$ The milk tea craze in the Philippines started in 2008 which can be divided into the first wave which started in December 2008 and the second wave which initiated in 2013 onwards. At an average internet use of 10 hours and 2 minutes per day and $99 \%$ on at least one social media platform, the internet users in the Philippines ranks first in internet usage worldwide. This makes web searches a rich source of information on the information-seeking behavior of the Filipino people. A Philippine Statistics Authority study hypothesized the increasing trend of milk tea consumption in the Philippines. The increase in milk tea consumption could lead to tooth decay and toothache. ${ }^{15}$

The primary aim of this study was to evaluate the oral health-seeking behaviors of Filipinos in terms of search trends using the search term "toothache" (TA) and search interest for milk tea using the search term "milk tea" (MT). Moreover, the objectives of the study include unraveling the search pattern of TA and MT (1) in the years 2017, 2018, and 2019; (2) seasonality across months and quarters; and (3) geographical differences among regions.

\section{METHODS}

\section{Design}

This study used data mining in the collection of internet search data and analyzed through spatio-temporal analyses of search trends using Google Trends (GT).

\section{Search Parameters}

Google Trends was mined for information regarding search trends using the search terms; TA and MT, the Philippines as location, 2017-2019 as years of interest, health as category, and web search as database. Specifically, the time period used for 2017 was from January 1, 2017 to December 31, 2017; the time period for 2018 was from January 1, 2018 to December 31, 2018; and the time period for 2019 was from January 1, 2019 to December 31, 2019.

\section{Data Collection}

Comma-separated value (CSV) files pertaining to the results of the searches according to interests over time and interests over sub-regions were downloaded. Notwithstanding the availability of charts in the panels of the website's graphic user interface, data from the CSV were rearranged and recomposed to make new graphs that were more representative of the results. The search trends from the relative search volumes (RSV) were represented by the bulk of searches made using the search terms over a period of time and over a specified location. The units used were peak popularity rate (PPR) or percentages scored from 0-100 where $0 \%$ is the minimum value meaning no searches or $100 \%$ for the maximum value meaning the most number of searches given the parameters.

\section{Statistical Analyses}

Brown-Forsythe and Welch Analysis of Variance (ANOVA) with a Games-Howell's post hoc test were used to determine significant temporal differences within individual search trends for TA and MT across the chosen timeline. A repeated measure (RM) two-way ANOVA with GeisserGreenhouse correction and Sidak's multiple comparison test was used to compare search trends for TA and MT across 2017,2018 , and 2019. To evaluate the seasonality of search trends throughout the twelve months or four quarters of the years, a Brown-Forsythe and Welch ANOVA was used. To further check for multiple comparisons, a post hoc Dunnett's T3 comparison was used for months and a Games-Howell's multiple comparisons were used for quarters. Spatial or geographic differences of search trends among the regions of the Philippines were assessed using a Friedman's test with Dunn's multiple comparison test.

Forecasting analysis was done by using the downloaded monthly RSV data from 2017 to 2019 and using the time series modeler in creating model types. The model was fitted and used to create a year-long, monthly prediction for the year 2020 .

Inferential statistical tests were done using GraphPad Prism version 8 with statistical significance set at $\mathrm{p}<0.05$, while forecasting was done using IBM SPSS version 26.

\section{RESULTS}

\section{Temporal Variability}

There is a statistically significant difference between years of search trends for TA as determined by a Brown-Forsythe and Welch ANOVA, F (2,59.81) = 1879, p<0.001. A GamesHowell's post hoc test revealed that the PPR percentages of RSV for TA in $2018(21.0 \pm 0.3, \mathrm{p}<0.001)$ and $2019(13.0 \pm 0.2$,

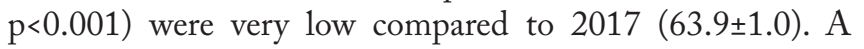
statistically significant difference between 2018 and 2019 $(p<0.001)$ is also observed. (Figure 1A)

The same test showed a significant difference between years of search trends for MT, F $(2,121.3)=13.4, \mathrm{p}<0.001$. 

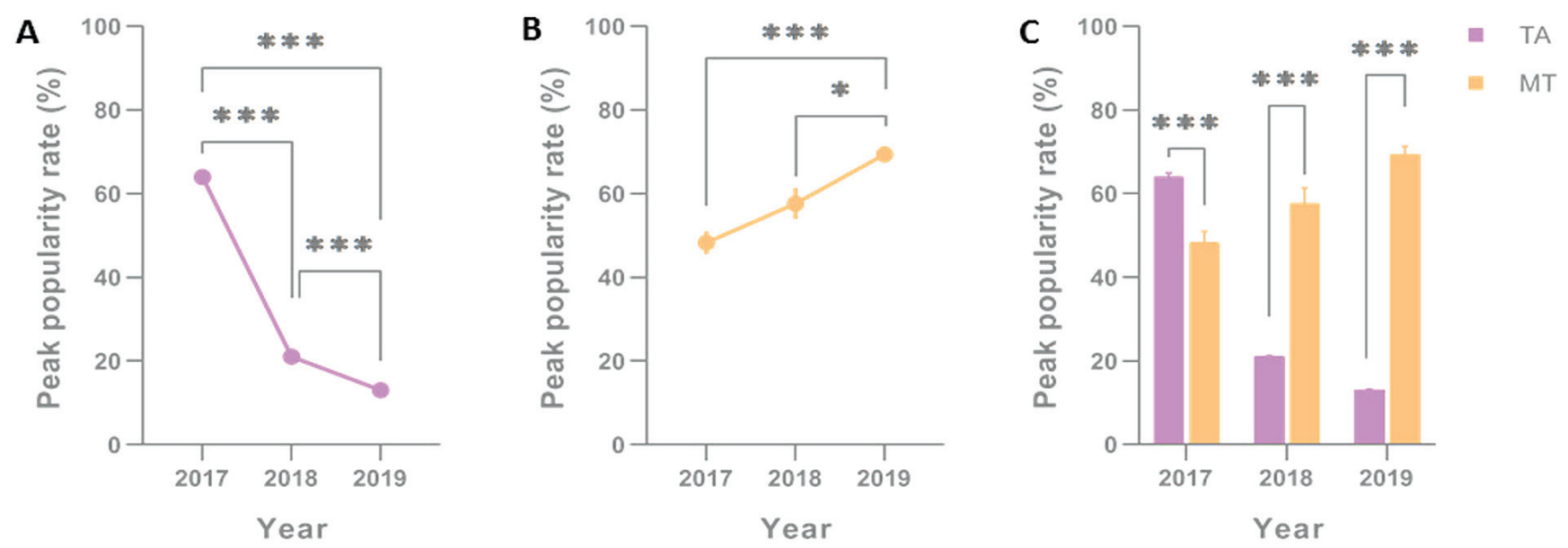

Figure 1. Differences in peak popularity rates of search trends across the years of 2017, 2018, and 2019 using the search terms (A) TA, (B) MT, and a comparison between (C) TA and MT. TA=toothache, MT=milk tea. Note: $p<0.05^{*}, p<0.001^{* * *}$

The multiple comparisons test uncovered that the PPR of RSV for MT in $2017(48.3 \pm 2.7, \mathrm{p}<0.001)$ and $2018(57.7 \pm 3.7$, $\mathrm{p}=0.018)$ were lower compared to $2019(69.3 \pm 1.9)$. There was no significant difference between 2017 and 2018 ( $\mathrm{p}=0.109)$. (Figure 1B)

An RM two-way ANOVA with Geisser-Greenhouse correction was conducted that examined the effect of years on search trends for TA and MT. There is a statistically significant interaction between the effects of years on search trends for TA and MT, F $(1,100)=161.4, \mathrm{p}<0.001$. A post hoc Sidak's multiple comparison test showed that searches for MT were significantly lower than TA in $2017(\mathrm{p}<0.001)$ but increased to the point that it is higher in 2018 ( $p<0.001)$, and $2019(\mathrm{p}<0.001)$. (Figure 1C)

\section{Seasonal Difference}

As determined by a Brown-Forsythe and Welch ANOVA, there is no statistically significant difference between of search trends for TA across months, $\mathrm{F}(11,129.1)$ $=0.49, \mathrm{p}>0.999$ (Figure $2 \mathrm{~A})$, and across quarters, $\mathrm{F}(3,139.2)$ $=0.45, \mathrm{p}=0.987$. (Figure 2B)

The same test showed a significant difference between months of search trends for MT, F $(11,92.71)=7.3, \mathrm{p}<0.001$. The Dunnett's T3 multiple comparisons test uncovered that the PPR of RSV for MT every May (60.6 $\pm 7.5, \mathrm{p}=0.050)$, June (58.4 $\pm 5.5, \mathrm{p}=0.019)$, July (58.3 $\pm 4.1, \mathrm{p}=0.005)$, August (66.5 $\pm 3.1, \mathrm{p}<0.001)$, September $(80.1 \pm 3.7, \mathrm{p}<0.001)$, October $(78.7 \pm 4.1, \mathrm{p}<0.001)$, November $(66.9 \pm 3.7, \mathrm{p}<0.001)$, and December $(58.8 \pm 4.3, \mathrm{p}=0.004)$ were higher compared to January (33.9 \pm 4.4$)$. There are no significant differences during February $(\mathrm{p}=0.984)$, March $(\mathrm{p}=0.748)$, and April $(\mathrm{p}=0.328)$ compared to January. (Figure $2 \mathrm{C}$ )

In testing for search trend differences for MT among quarters, a significant difference was found, F $(3,119.2)$ $=19.13, \mathrm{p}<0.001$. Moreover, a Games-Howell's multiple comparisons test found that the PPR of RSV for MT every second quarter $(57.3 \pm 4.1, \mathrm{p}=0.004)$, third quarter $(68.3 \pm 2.6$, $\mathrm{p}<0.001)$, and fourth quarter $(68.1 \pm 2.6, \mathrm{p}<0.001)$ were significantly higher compared to the first quarter $(39.0 \pm 3.0)$. But there were no differences between the third quarter $(\mathrm{p}=0.120)$ and fourth quarter $(\mathrm{p}=0.131)$ compared to the second quarter, and the third quarter $(\mathrm{p}>0.999)$ compared to the fourth quarter. (Figure 2D)

\section{Geographical Discrepancy}

According to Friedman's test, there is a statistically significant difference in PPR of RSV for TA on the Philippine regions, $\chi^{2}(15)=41.07, p<0.001$. Post hoc analysis with Dunn's multiple comparisons tests was conducted, which found significantly higher searches for TA in the regions of Caraga $(\mathrm{M}=61, \mathrm{p}=0.009)$, Eastern Visayas $(\mathrm{M}=63, \mathrm{p}=0.011)$, Western Visayas $(\mathrm{M}=59, \mathrm{p}=0.040)$, and Zamboanga Peninsula $(\mathrm{M}=73$, $\mathrm{p}=0.005)$ compared to Metro Manila $(\mathrm{M}=17)$. There were no differences in Bicol ( $p=0.979)$, Cagayan Valley $(p>0.999)$, Calabarzon ( $p>0.999)$, Central Luzon $(p>0.999)$, Central Visayas ( $p>0.999)$, CAR $(p>0.999)$, Davao Region $(p>0.999)$, Ilocos Region ( $p>0.999)$, MIMAROPA ( $\mathrm{p}=0.171)$, Northern Mindanao $(\mathrm{p}=0.070)$, and Region XII ( $\mathrm{p}=0.151)$ compared to Metro Manila. (Figure 3A)

The same significant difference in PPR of RSV for MT on the Philippine regions was found, $\chi^{2}(15)=41.07, \mathrm{p}<0.001$. Post hoc analysis with Dunn's multiple comparisons tests was conducted, which found significantly lower searches for TA in the regions of Caraga $(\mathrm{M}=39, \mathrm{p}=0.009)$, Eastern Visayas $(\mathrm{M}=37, \mathrm{p}=0.011)$, Western Visayas $(\mathrm{M}=41, \mathrm{p}=0.040)$, and Zamboanga Peninsula $(\mathrm{M}=27, \mathrm{p}=0.005)$ compared to Metro Manila $(\mathrm{M}=83)$. There were no differences in Bicol $(\mathrm{p}=0.979)$, Cagayan Valley ( $\mathrm{p}>0.999)$, Calabarzon $(\mathrm{p}>0.999)$, Central Luzon ( $p>0.999)$, Central Visayas ( $p>0.999)$, CAR ( $p>0.999)$, Davao Region ( $p>0.999)$, Ilocos Region $(p>0.999)$, MIMAROPA ( $\mathrm{p}=0.171)$, Northern Mindanao $(\mathrm{p}=0.070)$, and Region XII ( $\mathrm{p}=0.151$ ) compared to Metro Manila. (Figure 3B) 

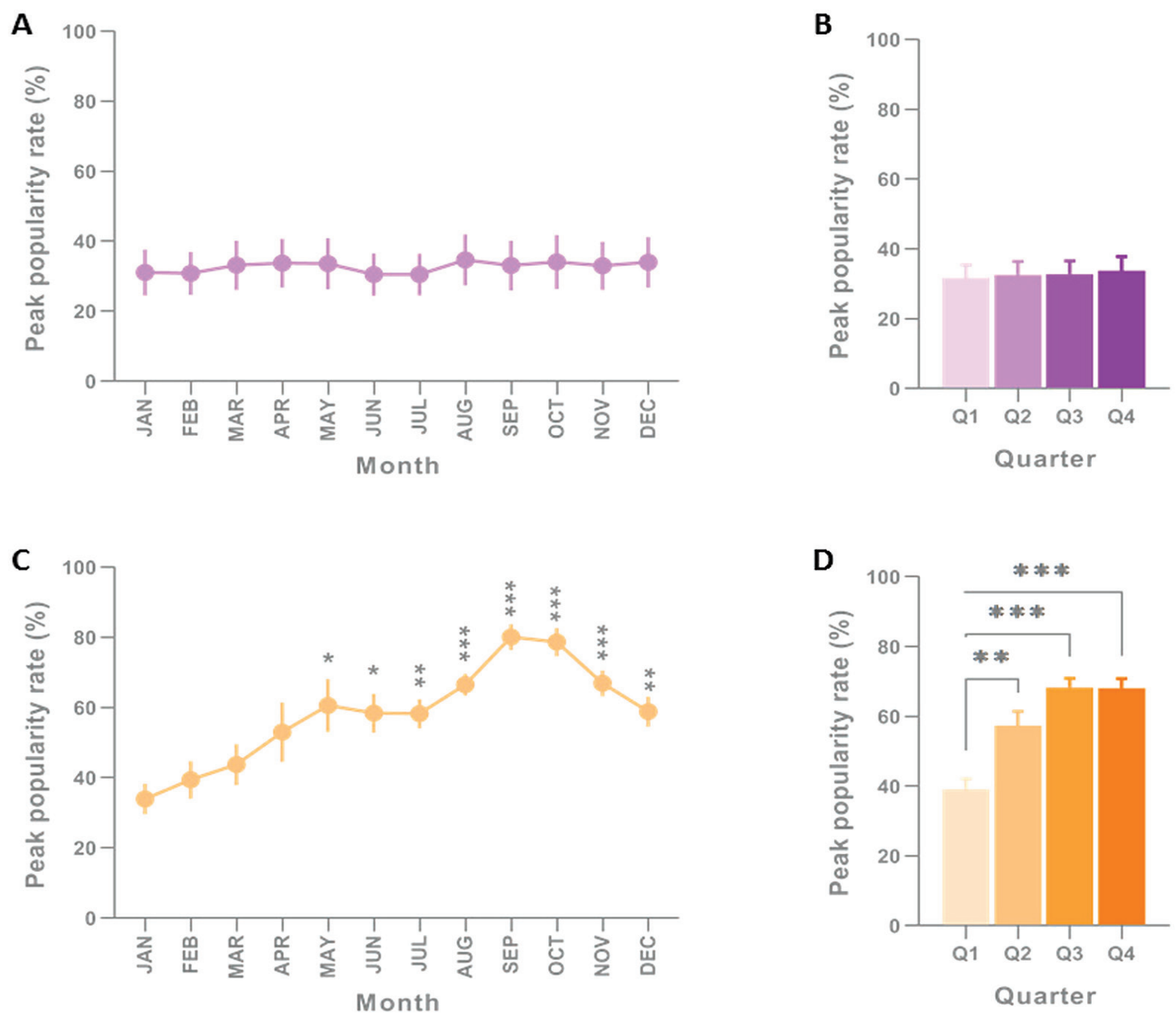

Figure 2. Seasonal differences in peak popularity rates of search trends across the years of 2017, 2018, and 2019 using the search terms (A) TA per month, (B) TA per quarter, (C) MT per month, (D) MT per quarter. TA=toothache, MT=milk tea, Q1=first quarter, Q2=second quarter, Q3=third quarter, Q4=fourth quarter. Note: $p<0.05^{*}, p<0.01^{* *}, p<0.001^{* * *}$

\section{Trend Forecast for 2020}

A year-long, monthly forecasted trend line was calculated for the year 2020. Based on the relative search volume data from 2017 to 2019, the Winters' Additive model was found to be the model type to fit the trend for both search terms.

The popularity trend will rise for TA at the start of the year in January with a forecasted rate (F) of 19\%, an upperclass limit (UCL) of $22 \%$, and a lower-class limit (LCL) of $16 \%$. The is also the lowest rate for TA, as it is predicted to rise with its highest rate in November $(\mathrm{F}=24 \%, \mathrm{UCL}=31 \%$, $\mathrm{LCL}=17 \%$ ) and slide $3 \%$ lower at the end of the year in December ( $\mathrm{F}=21 \%, \mathrm{UCL}=29 \%, \mathrm{LCL}=14 \%)$.

For MT, the search trend will start with a rise in forecast ( $\mathrm{F}=88 \%, \mathrm{UCL}=95 \%, \mathrm{LCL}=80 \%$ ). Its lowest point will occur in May ( $\mathrm{F}=83 \%, \mathrm{UCL}=91 \%, \mathrm{LCL}=75 \%)$, highest in September ( $\mathrm{F}=90 \%, \mathrm{UCL}=98 \%, \mathrm{LCL}=81 \%)$, and will end the year 3\% lower in December $(\mathrm{F}=85 \%, \mathrm{UCL}=93 \%, \mathrm{LCL}=77 \%)$ than January. (Figure 4)

\section{DISCUSSION}

Internet search trends have been shown to show epidemiologic prevalence and forecast new incidence of disease conditions. ${ }^{16-23}$ Other than Google ${ }^{20}$ that comprises $70 \%$ of the search industry, Facebook ${ }^{24}$ and Twitter ${ }^{25}$ have been data mined in the past.

Grounded on the results of this study, the low devaluing trend for TA that decreases substantially from 2017 to 2019 may indicate the Filipino's devaluation of oral health brought about by the $\mathrm{DOH}$, the government's ${ }^{1,5}$ and the Philippine Dental Association's (PDA) unsatisfactory programs. ${ }^{26}$ The extensive rise in web searches for MT show the Filipino's preference for food with high sugar content. ${ }^{3}$ This rise in trend can be attributed to a milk tea craze resulting from good marketing strategy and social media predominance. There have been two waves of milk tea obsession in the country. It has been said that this fad 
A

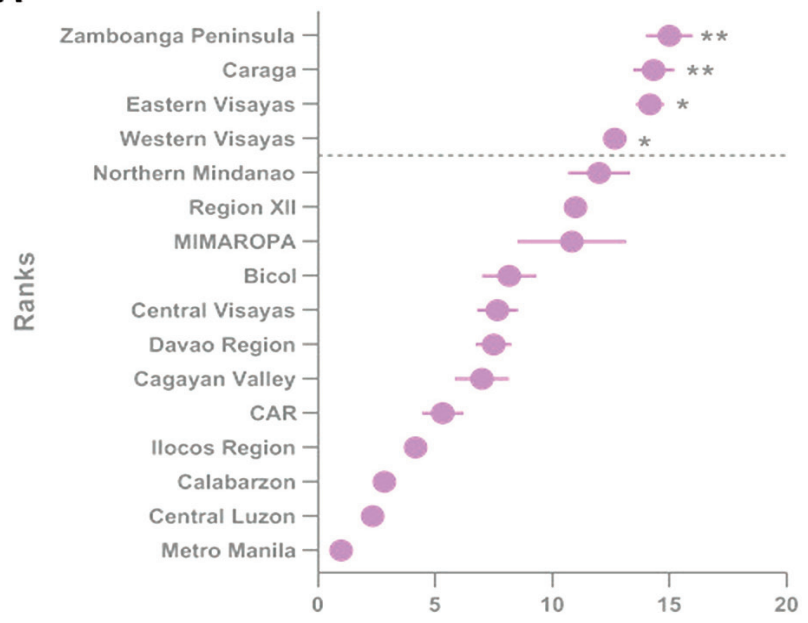

B

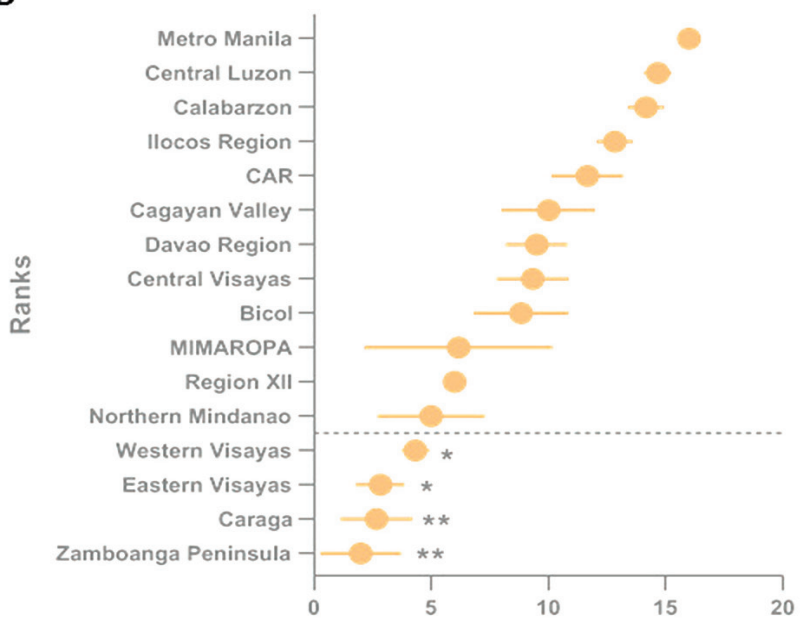

Figure 3. Comparison per region of peak popularity rates of search trends using the search terms (A) TA and (B) MT. TA=toothache, $M T=$ milk tea, MIMAROPA = Occidental Mindoro, Oriental Mindoro, Marinduque, Romblon and Palawan, CAR=Cordillera Autonomous Region. Note: $p<0.05^{*}, p<0.01^{* *}$

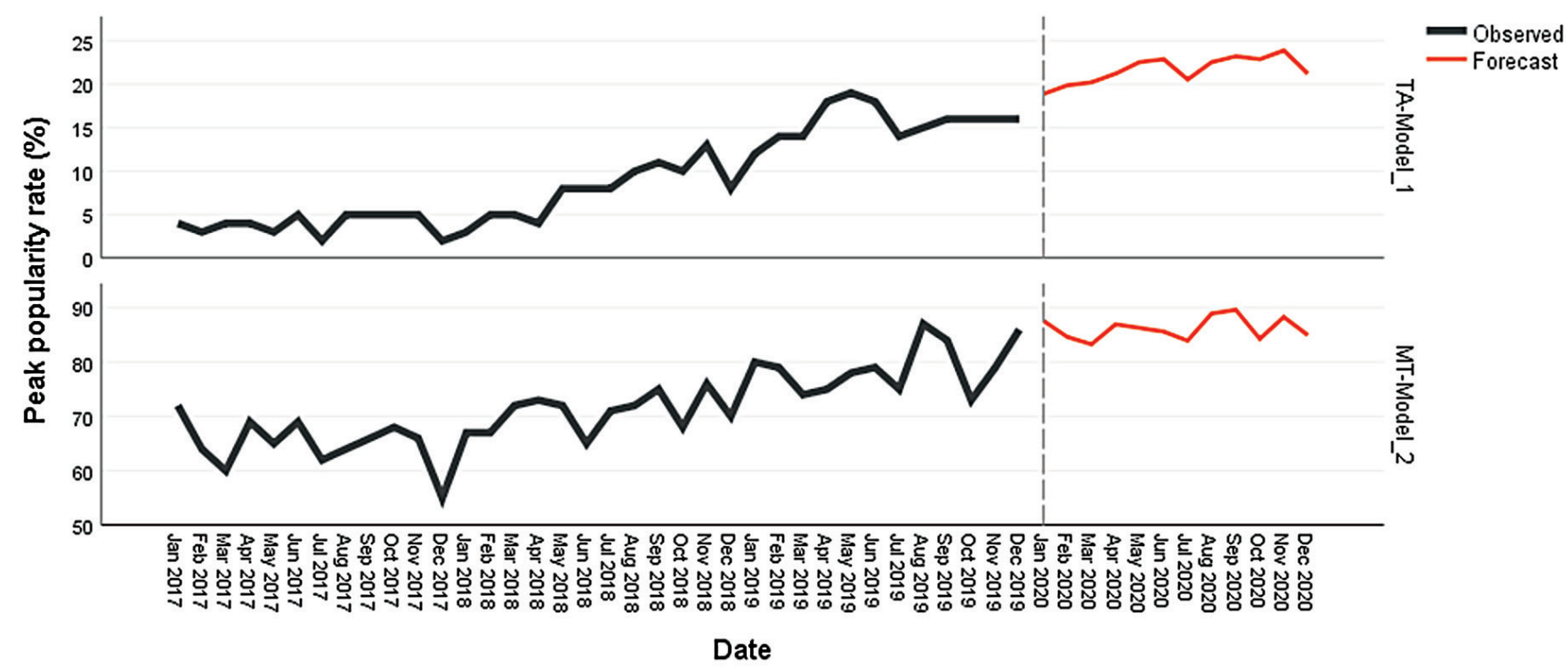

Figure 4. Forecasted trend for toothache (TA-Model_1) and milk tea (MT-Model_2).

is different from the first wave, as the second wave of milk tea fondness is due to the innovation of brands to offer something interesting. It is safe to assume that it will only continue to upsurge in the years to come. ${ }^{15}$ In this context, the $\mathrm{DOH}$, the PDA, and the government should study policies and schemes similar to the graphic ads used by cigarette companies on the negative health effects of smoking. These adverts have been shown to be effective in low and middleincome countries. ${ }^{27,28}$ Placing illustrative ads on MT or other sugary food, showing the ill-effects of dental caries, may turn the tides in the oral health advocates' campaign against dental caries and TA.

Although there was low and no significant change in the search for TA over months and quarters, this can be optimistically taken and it is good to know that people are still searching about TA. On another note and based on the relative searches, this could also mean that people are self-medicating and are trying to offset the lack of dental insurance ${ }^{26}$ and dental programs in the country. ${ }^{1,5}$ Meanwhile, the seasonality of MT searches shown by peaks in eight of twelve months and three of four quarters in a year can be taken positively by government and non-government educations as information on when to intensify the oral health education and dental services programs. This could also be valuable for educational institutions as MT searches start to increase in June when most of the classes in the Philippines commence and start to decrease during March, October, and December or months that fall on holiday 
seasons (e.g. summer, semester break, and Christmas). Like the ill-advised trend in using dental braces for fabricated social status ${ }^{29}$ without ascertaining its risk ${ }^{30}$, the rising craze for MT could be an effect of school-aged Filipinos trying to increase their popularity.

The geographical discrepancy in searches for TA shows higher volumes in Zamboanga Peninsula, Caraga, Eastern Visayas, and Western Visayas. The first two regions belong to Mindanao and the last two belong to Visayas. This could be taken to understand that these regions are to be commended for their oral health-seeking behavior. Unfortunately, this can also be interpreted as regions outside of Luzon where the capital of Metro Manila is located. In addition, this could mean that these regions are remotely located from the sources of oral health services or these regions are composed of people that devalue the practice of dentistry. Knowing that Eastern Visayas and Western Visayas are densely populated areas that comprise two-thirds of the Visayas Area adds graveness to the impact of TA incidence.

There is a projected rising interest for TA at $24 \%$ in November 2020. Unfortunately, this is still 59\% lower than the lowest popularity rate for MT. The concerned government and private organizations should double down and capitalize on this trend by fortifying the advocacy of oral health.

\section{CONCLUSION}

The outcomes of this study indicate that there is an alarming increase in interest for MT and a decreasing trend for TA among Filipinos within the last three years. This report also indicates that a seasonal difference can be observed in MT but not in TA. This information could be valuable in determining the health-seeking behavior of Filipinos and a cautionary reminder to increase the preventive measures for dental caries or strengthen the public health education crusade for oral health care. The temporal difference according to months and quarter should determine the frequency of oral health education needed. The geographical difference, which pertains to regions most interested in TA (Zamboanga Peninsula, Caraga, Eastern Visayas, and Western Visayas), could be a call for assistance due to a high incidence of dental caries. Likewise, regions like Metro Manila and others that scored high on search trends for MT should be considered a threshold to inform the residents of these places that too much consumption of sugar can be detrimental to oral health. In 2020, the search interest for TA will still be insubstantial compared to MT although the former will have a rising trend compared to the latter.

It should be stressed that this study is not without limits. The data used in the analyses are limited by information from GT and other sources of trends can be used like Facebook and Twitter. The cohort can also be changed to include other countries in Southeast Asia, Asia, or the World. Another cohort of comparison can be between developed countries. To increase the strength of the temporal analysis, the length of time can be increased to include the last decade. Actual DMFT data from the Department of Health or municipal health can also be correlated with these results. Other food craze or nutritional trends should be explored as well. Finally, traditional and contemporary time series models can be used to forecast the future trend of dental caries.

Despite these limitations, this study is a good benchmark to show that the campaign against dental caries in the Philippines is far from over.

\section{Acknowledgments}

The authors wish to extend their gratitude to the faculty members of the School of Dentistry, Southwestern University PHINMA and the research members of the Department of Stomatognathic Function and Occlusal Reconstruction, Tokushima University Graduate School of Biomedical Sciences.

\section{Statement of Authorship}

All authors participated in data collection and analysis, and approved the final version submitted.

\section{Author Disclosure}

All authors declared no conflicts of interest.

\section{Funding Source}

This study was partially funded by the Fujii-Otsuka International Scholarship Award, the Oral Sciences Award of Tokushima University Graduate School of Biomedical Sciences, and the International Association for Human Caring Shirley C. Gordon Award.

\section{REFERENCES}

1. DOH. Dental Health Program. Department of Health. [Internet] 2015. [Cited 2019 October 20]. Available from: https://www.doh. gov.ph/dental-health-program.

2. Yabao RN, Duante CA, Velandria FV, et al. Prevalence of dental caries and sugar consumption among 6-12-y-old schoolchildren in La Trinidad, Benguet, Philippines. Eur J Clin Nutr. 2005;59(12): 1429-1438.

3. Vieira AR, Marazita ML, Goldstein-McHenry T. Genome-wide scan finds suggestive caries loci. J Dent Res. 2008;87(5):435-439.

4. Heinrich-Weltzien R, Monse B, Benzian H, Heinrich J, KromeyerHauschild K. Association of dental caries and weight status in 6- to 7-year-old Filipino children. Clin Oral Investig. 2013;17(6): $1515-1523$.

5. DOH. Oral Health Program. Department of Health.. [Internet] 2015. [Cited 2019 November 30,]. Avalable from: https://www.doh.gov.ph/ oral-health-program

6. Monse B, Benzian H, Naliponguit E, Belizario V, Schratz A, van Palenstein Helderman W. The Fit for School Health Outcome Study - a longitudinal survey to assess health impacts of an integrated school health programme in the Philippines. BMC Public Health. 2013;13:256.

7. Monse B, Benzian H, Araojo J, et al. A silent public health crisis: untreated caries and dental infections among 6- and 12-year-old children in the Philippine National Oral Health Survey 2006. Asia Pac J Public Health. 2015;27(2):NP2316-25. 
8. Ahmad AF, Rich L, Koch H, et al. Effect of adding milk to black tea on vascular function in healthy men and women: a randomised controlled crossover trial. Food Funct. 2018;9(12):6307-14.

9. Chen F, Yan L, Lin L, et al. Independent and joint effects of tea and milk consumption on oral cancer among non-smokers and non-drinkers: a case-control study in China. Oncotarget. 2017;8(30):50091-50097.

10. Chiu HF, Lin TY, Shen YC, Venkatakrishnan K, Wang CK. Improvement of green tea polyphenol with milk on skin with respect to antioxidation in healthy adults: a double-blind placebo-controlled randomized crossover clinical trial. Food Funct. 2016;7(2):893-901.

11. Korir MW, Wachira FN, Wanyoko JK, Ngure RM, Khalid R. The fortification of tea with sweeteners and milk and its effect on in vitro antioxidant potential of tea product and glutathione levels in an animal model. Food Chem. 2014;145:145-53.

12. Reddy VC, Vidya Sagar GV, Sreeramulu D, Venu L, Raghunath M. Addition of milk does not alter the antioxidant activity of black tea. Ann Nutr Metab. 2005;49(3):189-95.

13. Pfeuffer M, Schrezenmeir J. Addition of milk prevents vascular protective effects of tea. Eur Heart J. 2007;28(10):1265-1266; author reply $1266-1267$.

14. Min JE, Green DB, Kim L. Calories and sugars in boba milk tea: implications for obesity risk in Asian Pacific Islanders. Food Sci Nutr. 2017;5(1):38-45.

15. Supranes MV. The "Milk Tea War": A case study on using social media as a source of business intelligence. 14th National Convention on Statistics; October 1-3, 2019, 2019; Quezion City, Philippines.

16. Alicino C, Bragazzi NL, Faccio V, et al. Assessing Ebola-related web search behaviour: insights and implications from an analytical study of Google Trends-based query volumes. Infect Dis Poverty. 2015;4:54.

17. Ho HT, Carvajal TM, Bautista JR, et al. Using Google Trends to Examine the Spatio-Temporal Incidence and Behavioral Patterns of Dengue Disease: A Case Study in Metropolitan Manila, Philippines. Trop Med Infect Dis. 2018;3(4).

18. Mohamad M, Kok HS. Using Google Trends Data to Study Public Interest in Breast Cancer Screening in Malaysia. Asian Pac J Cancer Prev. 2019;20(5):1427-32.
19. Morsy S, Dang TN, Kamel MG, et al. Prediction of Zika-confirmed cases in Brazil and Colombia using Google Trends. Epidemiol Infect. 2018;146(13):1625-7.

20. Nuti SV, Wayda B, Ranasinghe I, et al. The use of google trends in health care research: a systematic review. PLoS One. 2014;9(10):e109583.

21. Ocampo AJ, Chunara R, Brownstein JS. Using search queries for malaria surveillance, Thailand. Malar J. 2013;12:390.

22. Patthi B, Kumar JK, Singla A, et al. Global Search Trends of Oral Problems using Google Trends from 2004 to 2016: An Exploratory Analysis. J Clin Diagn Res. 2017;11(9):ZC12-ZC16.

23. Xu Q, Gel YR, Ramirez Ramirez LL, Nezafati K, Zhang Q, Tsui KL. Forecasting influenza in Hong Kong with Google search queries and statistical model fusion. PLoS One. 2017;12(5):e0176690.

24. Abreo NAS, Thompson KF, Arabejo GFP, Superio MDA. Social media as a novel source of data on the impact of marine litter on megafauna: The Philippines as a case study. Mar Pollut Bull. 2019;140:51-9.

25. Bautista JR, Lin TT. Tweeting Social Support Messages After a Non-Celebrity's Death: The Case of the Philippines' \#Fallen44. Cyberpsychol Behav Soc Netw. 2015;18(11):641-6.

26. Dalanon J, Diano L, Esguerra R, et al. The Cebuano Mothers' Willingness to Pay for Dental Healthcare. The Journal of the Philippine Dental Association. 2018;65(2):33-7.

27. Durkin S, Bayly M, Cotter T, Mullin S, Wakefield M. Potential effectiveness of anti-smoking advertisement types in ten low and middle income countries: do demographics, smoking characteristics and cultural differences matter? Soc Sci Med. 2013;98:204-13.

28. Wakefield M, Bayly M, Durkin S, et al. Smokers' responses to television advertisements about the serious harms of tobacco use: pretesting results from 10 low- to middle-income countries. Tob Control. 2013;22(1):24-31.

29. Sorooshian S, Kamarozaman AA. Fashion braces: an alarming trend. Sao Paulo Medical Journal. 2018;136(5):497-8.

30. Estremera S. 19-year-old fake dentist installing braces. Sunstar Philippines. https://www.sunstar.com.ph/article/1748795? rss=1. Published 2018. Accessed November 30, 2019. 